\title{
Propuesta de indicadores para evaluar el turismo sostenible. Cantón Otavalo
}

\section{Proposal of indicators to evaluate sustainable tourism. Canton Otavalo}

DOI: $10.46932 / \mathrm{sfjdv2n3-036}$

Received in: May 1st, 2021

Accepted in: Jun 30th, 2021

\author{
Jesús Francisco González Alonso \\ Dr.C. \\ Universidad Otavalo. \\ E-mail: jgonzalez@uotavalo.edu.ec. \\ Belky Nerea Orbes Revelo \\ Ms.C. \\ Imbabura. Ecuador. Universidad Otavalo. \\ E-mail: borbes@uotavalo.edu.ec.
}

\section{RESUMEN}

En estos momentos el turismo se ha convertido en un importante incentivo para el desarrollo local, cabe destacar que el cambio de paradigma está en la dinamización de la actividad turística potenciando los recursos naturales, la cultura de la región, el desarrollo económico y la mayor conciencia por la ecología. Esto permitirá poder desarrollar nuevos emprendimientos sociales lo que permitirán una sostenibilidad turística además de la posibilidad de generación de empleo.

En la República del Ecuador existen diversos destinos turísticos uno de ellos de mayor relevancia es: Otavalo el cual es visitado por turistas nacionales e internacionales su atracción es el acervo cultural que ha permitido mantener su identidad, ofreciendo su milenaria leyendas, mitos, costumbres y tradiciones. También es considerada como la capital de las artesanías, gracias a la diversidad de productos artesanales típicos y su plaza o mercado de Los Ponchos donde se concentran cientos de artesanos a exponer y comercializar sus artesanías.

En el proceso de la planeación turística desarrollado actualmente se fundamenta bajo los objetivos de la sustentabilidad las que nos permiten recolectar, procesar, presentar y analizar la información para evaluar las actuaciones que se llevan a cabo en los destinos turísticos del cantón Otavalo.

El objetivo de este trabajo es proponer un sistema de indicadores que permitirán medir la sostenibilidad del turismo en el cantón Otavalo. Esta herramienta fue diseñada atendiendo a las necesidades de los estudiantes de la carrera de Licenciatura en Turismo de la Universidad Otavalo, quienes deberán realizar prácticas de vinculación con la sociedad y serán los evaluarán la sostenibilidad de los destinos turísticos del cantón.

Finalmente analizaremos los resultados de la propuesta metodológica de indicadores para evaluar el turismo sostenible, los que han sido evaluados por estudiantes y profesores de la carrera.

Palabras clave: sostenible, indicadores, social, económico, ambiental

\begin{abstract}
In these moments tourism has become an important incentive for local development, it is worth noting that the paradigm shift is in the dynamization of tourism activity, enhancing natural resources, the region's culture, economic development and greater awareness. for the ecology This will allow the development of new social undertakings, which will allow tourism sustainability as well as the possibility of generating employment.
\end{abstract}


In the Republic of Ecuador there are several tourist destinations one of them of greater relevance is: Otavalo which is visited by national and international tourists its attraction is the cultural heritage that has allowed to maintain its identity, offering its ancient legends, myths, customs and traditions . It is also considered the capital of handicrafts, thanks to the diversity of typical handicrafts and its plaza or market of Los Ponchos where hundreds of artisans are concentrated to exhibit and market their crafts.

In the process of the tourist planning currently developed, it is based on sustainability objectives that allow us to collect, process, present and analyze the information to evaluate the actions that are carried out in the tourist destinations of the Otavalo canton.

The objective of this work is to propose a system of indicators that will measure the sustainability of tourism in the canton of Otavalo. This tool was designed to meet the needs of the students of the Bachelor of Tourism degree at the Otavalo University, who will have to practice internships with society and will be evaluated the sustainability of the tourist destinations of the canton.

Finally, we will analyze the results of the methodological proposal of indicators to evaluate sustainable tourism, which have been evaluated by students and professors of the race.

Key words: sustainable, indicators, social, economic, environmental.

\section{INTRODUCCIÓN}

Es indudable que la actividad turística constituye una de las principales fuentes de riqueza que genera importantes beneficios de tipo económico, social y medioambiental.

A pesar de ello, no es un sector de impacto "cero" sobre el medio ambiente y los recursos culturales de los destinos. Para reducir al máximo sus impactos negativos, desde organismos como la Organización Mundial del Turismo (OMT) se insta a los gobiernos a considerar la sostenibilidad como objetivo global.

Nace así lo que se denomina Turismo Sostenible. Bajo este objetivo, el mercado turístico se desarrolla actualmente en un contexto de creciente competencia, en el que surgen destinos emergentes que intentan atraer una demanda creciente mediante modelos turísticos tradicionales que hacen peligrar la actividad a largo plazo.

Por su parte, los destinos más consolidados apuestan por un nuevo modelo turístico diverso, de calidad y sostenible social, económica y ambientalmente para conseguir mejorar su competitividad. Independiente de su grado de consolidación, los destinos necesitan contar con algún instrumento y herramientas para evaluar su situación y definir las actuaciones necesarias para su transformación en destinos más sostenibles.

Para ello, se debe contar con estas herramientas para medir el grado de sostenibilidad del destino turístico. Una de las herramientas más utilizadas en la práctica es la definición de un sistema de indicadores.

Asimismo, gran parte de estos trabajos que evalúan la sustentabilidad turística se formulan teóricamente el sistema sin llegar a cuantificarlo totalmente, lo que les resta operatividad y dificulta su utilización en la práctica. La definición de este tipo de instrumentos o herramienta es aún más necesaria 
en el marco de planeación actual, donde se da un mayor protagonismo a la dimensión regional para nuestro caso de estudio la cantonal, de forma que las intervenciones que se lleven a cabo en el sector se plantearán desde el propio territorio al que van destinadas.

El principal motivo es la existencia de una comunicación defectuosa a la hora de hacer llegar la información contenida en los planes turísticos a los agentes que actúan a nivel local (cantonal), dado el lenguaje complejo empleado en los informes y comunicaciones.

En este contexto, es necesario implicar más a los estudiantes de la carrera de turismo de la Universidad Otavalo mejorando su conocimiento sobre los aspectos relacionados con la sostenibilidad de la actividad turística mediante instrumentos y herramientas de medición que les permitan visualizar los aspectos sobre los que es necesario actuar.

Asimismo, estos instrumentos pueden contribuir a hacer más objetivo el éxito o fracaso del proceso de actuación estableciéndose metas y plazos reales para cumplirlas, de forma que pueda transmitirse los resultados que se van obteniendo.

En este trabajo nos planteamos como objetivo general:

Definir un sistema de indicadores y herramientas de turismo sostenible pensado para destinos turísticos más consolidados, teniendo en consideración la dimensión territorial de los procesos de planificación turística, que permita comparar la sostenibilidad de la actividad turística de los destinos para que los estudiantes de la licenciatura en turismo puedan aportar resultados en las actividades de vinculación conla sociedad.

Consideramos que la utilización de este instrumento permitiría mejorar el conocimiento de la situación del sector para detectar y prevenir los problemas en su inicio, mejorar la toma de decisiones de los agentes implicados en la planeación de las actividades del sector, para en un corto plazo poder diseñar medidas correctivas adecuadas si fuera necesario, etc.

Además, el sistema de indicadores es una herramienta que puede adaptarse a las características del segmento turístico que se esté analizando, permitiendo así la formulación de una actuación diferenciada para cada ámbito del espacio turístico.

Estos índices sintéticos facilitan los análisis comparativos y las prácticas de benchmarking entre destinos, permitiendo asimismo guiar las decisiones que los agentes implicados en la planificación deben adoptar para alcanzar el objetivo final del cantón Otavalo.

Para conseguir el objetivo planteado estructuramos este trabajo como sigue.

En el siguiente apartado formulamos una definición práctica de Turismo Sostenible desde una perspectiva institucional adoptando una posición de convergencia, desglosando este objetivo en tres grandes dimensiones (social, económica y ambiental), a las que damos un contenido pormenorizado 
siguiendo las directrices de la Organización Mundial del Turismo.

Asimismo, como instrumento de medición, definiremos un sistema de indicadores adaptado al análisis conceptual previo y compuesto por los indicadores más relevantes para cada aspecto que se propone evaluar, en función de su frecuencia de uso y la facilidad asociada a su interpretación.

En el tercer apartado realizamos un análisis metodológico que permite caracterizar el proceso de elaboración de indicadores, identificando los "pasos básicos" que deben seguirse para la construcción de un indicador.

Con las conclusiones extraídas, en el cuarto apartado formulamos los procedimientos para obtener indicadores sintéticos, que tengan asociada una menor subjetividad y no requieran un análisis muy complejo al interpretar los valores obtenidos.

Por otro lado, presentamos un procedimiento inspirado en la metodología formulada por los profesores Díaz-Balteiro y Romero, (2004) basada en la Programación por Metas, que nos permite obtener distintos indicadores sintéticos en función de cómo se utilice la información proporcionada por las variables de desviación.

En el quinto apartado realizamos una aplicación empírica de los instrumentos definidos en los apartados precedentes, utilizando para ello el caso de los destinos turísticos del cantón Otavalo. Así, ilustramos la forma en la que pueden ser usados estos instrumentos, venciendo las carencias de otros trabajos realizados en este campo.

En el análisis de los resultados determinamos los rasgos característicos de los resultados obtenidos por los criterios de los estudiantes y profesores de la carrera de turismo en la Universidad Otavalo.

Así, con la información obtenida en la aplicación de este sistema de indicadores, se podrá formular nuevas estrategias de actuación, identificando los destinos mejor posicionados y analizando el tipo de medidas que están llevando a cabo, de forma que pueda adaptar éstas a la realidad de su destino, facilitándose así la posibilidad de realizar prácticas de benchmarking.

El trabajo que presentamos finaliza con un apartado donde recogemos las principales conclusiones extraídas del estudio.

\section{TURISMO SOSTENIBLE: CONCEPTO Y MEDICIÓN.}

A pesar de su aceptación a nivel internacional, aún existe un intenso debate en cuanto a la definición y puesta en marcha de un modelo de desarrollo sostenible adaptado a la realidad del sector turístico.

Sí existe un acuerdo relativo al término empleado al analizar los diferentes modelos turísticos desarrollados bajo objetivos de sostenibilidad es el de turismo sostenible. 
Pero; ¿Qué entendemos por turismo sostenible? Del análisis de las respuestas a esta pregunta puede concluirse que, a grandes rasgos, pueden distinguirse cuatro interpretaciones diferentes (Clarke, 1997; Hardy et al., 2002) que se han ido sucediendo cronológicamente.

Una primera interpretación es la que se realiza desde una posición de polos opuestos, en la que se considera al turismo sostenible como una forma de turismo alternativo opuesta al turismo de masas. Es decir, un turismo que plantea una interrelación más estrecha con la naturaleza, con una mayor preocupación por la conservación de los recursos naturales y sociales en los que las actividades tienen lugar. Con esta visión del concepto, el turismo sostenible no suponía más que la puesta en marcha de actividades turísticas a menor escala.

Una segunda interpretación se realiza desde una posición de continuum. En este caso se considera que los distintos tipos de actividad turística conforman una serie ordenada delimitada por dos tipologías extremas: el turismo de masas y el turismo sostenible. Dado que todas las actividades comparten la misma base de recursos, se considera que si no se realiza una gestión adecuada toda actividad tiene el potencial de converger hacia un turismo de masas.

Por ello, el objetivo es desarrollar actividades turísticas que se ajusten lo máximo posible al tipo de actividad a pequeña escala calificada como sostenible. Estas dos interpretaciones son muy criticadas y señaladas como improductivas, al adaptar una visión sectorial basada en las características de lademanda de actividades de turismo alternativo y en cuestiones de marketing (Holden, 2000), no considerando al turismo como un vehículo para la consecución del desarrollo sostenible.

Asimismo, gran parte de los aspectos críticos de las mismas se centran en su simplicidad, al consideraral turismo sostenible como estado y una realidad homogénea y su impracticabilidad, al reducir a la pequeña escala la consideración de actividad sostenible.

Ante estas críticas, una tercera interpretación se desarrolló desde una posición de movimiento. En este caso el turismo sostenible se define como un objetivo a alcanzar más que un estado aplicable únicamente a las actividades turísticas a pequeña escala. Para hacer operativo este objetivo, desde esta posición se apuesta por formular las directrices a seguir por los agentes del sector para llevar a cabo prácticas más sostenibles (Hardy et al., 2002).

Finalmente, una cuarta interpretación, que busca un concepto más operativo, se desarrolla desde una posición de convergencia. Según esta posición, el turismo sostenible se consolida como el objetivo a alcanzar en todos los segmentos del sector turístico, independientemente de la escala a la que se desarrolle la actividad.

No obstante, se reconoce que la obtención de una definición precisa y ampliamente aceptada del turismosostenible es menos importante que la formulación del camino a seguir. Se apuesta así por 
formular el objetivo de forma que permita establecer claramente la estrategia a seguir, facilitándose la determinación del papel que el desarrollo de la actividad turística juega en la estrategia global de sostenibilidad de una sociedad (Hunter, 2002).

En los últimos años, dentro de la posición de convergencia se desarrollan gran parte de los estudios centrados en el análisis del turismo sostenible. En nuestro estudio adoptamos esta posición como punto de partida para buscar una definición operativa del turismo sostenible.

En este contexto, para obtener una definición operativa de turismo sostenible realizamos:

Formular una definición general que nos ayude a comprender qué se entiende por turismo sostenible e identificar los aspectos básicos sobre los que es necesario actuar para alcanzar el objetivo global de sostenibilidad.

Para definir el turismo sostenible adoptamos la perspectiva de análisis institucional basada en la satisfacción de las necesidades de las generaciones presentes y futuras como eje fundamental, siguiendo así la línea de instituciones internacionales como la OMT. Esta perspectiva cuenta con un alto respaldo internacional y se ajusta al marco bajo el que se configuran los procesos de planificación del sector, lo que facilita el cumplimiento de los objetivos de este trabajo.

Siguiendo esta perspectiva, para la formulación de la definición general de turismo sostenible analizamoslas conferencias, reuniones, informes, etc. realizados por las instituciones internacionales, centrándonos en las cuestiones relativas al sector turístico.

De este análisis podemos concluir que el turismo sostenible puede definirse como aquél que “...satisface las necesidades de los turistas y regiones anfitrionas presentes, al mismo tiempo que protege y mejora las oportunidades del futuro. Está enfocado hacia la gestión de todos los recursos de tal forma que se satisfagan todas las necesidades económicas, sociales y estéticas al tiempo que se respeta la integridad cultural, los procesos ecológicos esenciales, la diversidad biológica y los sistemas de apoyo a la vida" (World Tourism Organization, 1993).

Para conseguir este objetivo el consenso internacional deja claras las directrices generales a seguir en los procesos de desarrollo del sector. En este sentido, es necesario desarrollar políticas turísticas que garanticen la protección de los recursos naturales, sociales y culturales que sustentan la actividad y la capacidad de los mismos para la satisfacción de las necesidades de los turistas y las poblaciones residentes presentes y futuras (Sharpley, 2000; Liu, 2003).

Para ello, un modelo turístico sostenible requiere (World Tourism Organization, 2004):

1- Dar un uso óptimo a los recursos ambientales, manteniendo los procesos ecológicos esenciales y ayudando a conservar los recursos naturales y la diversidad biológica.

2- Respetar la autenticidad sociocultural de las comunidades de residentes, conservando su patrimonio 
cultural y sus valores tradicionales, así como contribuir al entendimiento y a la tolerancia intercultural.

3- Asegurar unas actividades económicas viables a largo plazo, que generen beneficios socioculturales bien distribuidos y que contribuyan a la reducción de la pobreza.

4- Una amplia participación informada de todos los implicados en el proceso de planificación y gestión del destino, así como un liderazgo político firme para lograr una colaboración amplia y establecer un consenso.

5- Alto grado de satisfacción de los turistas, que propicie una mayor conciencia por parte de éstos sobre los problemas de la sostenibilidad y fomente por su parte prácticas más sostenibles.

Obtenida esta definición general, en segundo lugar, identificamos los aspectos básicos sobre los que es necesario actuar para alcanzar una situación más sostenible.

Para ello tomamos como referencia las directrices de la Organizaciòn Mundial del Turismo en cuanto a las cuestiones que deben ser consideradas al planificar un destino bajo objetivos de sostenibilidad (World Tourism Organization, 2004).

Esta institución ofrece un listado de aspectos relativos a la sostenibilidad turística, de forma que la consideración o no de cada uno de ellos dependerá del análisis que se quiera realizar y del tipo de destino estudiado.

Así, la definición de turismo sostenible que presentamos está abierta a la inclusión de nuevos aspectos que, bajo el punto de vista que deban ser considerados. El conjunto de aspectos básicos seleccionados es agrupado en función de la dimensión conceptual a la que están referidas.

Siguiendo otros estudios de la materia (Ávila et al., 2002; Dachary y Arnáiz, 2002; Fullana y Ayuso, 2002), presentamos el turismo sostenible dividido en tres dimensiones:

1- Social

2- Económica

3- Medioambiental.

La asignación de los aspectos a cada dimensión se ha realizado según su naturaleza tomando como base estudios precedentes, cubriendo así la falta de directrices al respecto.

En el caso de la dimensión social, se recogen las cuestiones relacionadas con los impactos socioculturales de la actividad sobre el entorno y la población residente.

Estas cuestiones sociales se agrupan en cuatro grandes aspectos (tabla No1).

Un primer aspecto lo conforman las cuestiones que influyen en el bienestar de la comunidad residente enel destino tales como la satisfacción de la población local, la evaluación y el control de los 
efectos socioculturales del desarrollo turístico sobre la población residente o el acceso real de la población residente a los principales recursos.

Un segundo aspecto social es la conservación del patrimonio cultural construido, cuya explotación económica debe permitir aprovechar al máximo los beneficios sociales de esta actividad turística, buscando un equilibrio entre la protección y el uso del patrimonio como recurso.

En tercer lugar, consideramos la participación de la comunidad local en el desarrollo turístico, consiguiendo una mayor concienciación, implicación y participación eficaz de la comunidad en el proceso de planificación.

Finalmente, se consideran las cuestiones relativas a la seguridad y los aspectos sanitarios ligados a la visita al destino.

Tabla No1: Variable social del Turismo Sostenible.

\begin{tabular}{|c|c|}
\hline Aspectos Sociales & Elementos básicos que integran. \\
\hline 1-Bienestar $\begin{array}{c}\text { de las comunidades } \\
\text { receptoras. }\end{array}$ & 1.1-Satisfacción de los residentes. \\
\cline { 2 - 2 } & 1.2-Efectos socio cultural. \\
\cline { 2 - 2 } & 1.3-Acceso de los residentes a los recursos. \\
\hline 2-Conservación cultural. & 2.1-Conservaciòn del patrimonio. \\
\hline 3-Participación comunitaria. & 3.1- Participación de la comunidad. \\
\hline 4-Salud y seguridad & 4.1-Aspectos sanitarios. \\
\cline { 2 - 2 } & 4.2-Seguridad pública. \\
\hline
\end{tabular}

Fuente: Propia.

Por su parte, la dimensión económica recoge los aspectos relacionados con la viabilidad a largo plazo dela actividad turística como actividad económica, que se muestran en la figura No 2.

El primero de ellos es el grado de aprovechamiento de los beneficios económicos del turismo por partede los agentes del sector.

En este grupo se contemplan cuestiones básicas como la estacionalidad de la actividad, el empleo turístico, los efectos indirectos de la actividad en otros sectores o los niveles de competitividad del producto turístico del destino.

El segundo aspecto considerado es el control de las actividades turísticas a través del número de turistasy la intensidad de uso turístico.

En tercer lugar, encontramos el aspecto de la ordenación y control del lugar de destino, en él se consideran tres cuestiones básicas:

1- La integración del sector turístico en los procesos de planificación.

2- Los mecanismos de control de la puesta en marcha del modelo turístico

3- El sistema de transportes que garantice la accesibilidad y movilidad de la demanda.

En cuarto lugar, se consideran cuestiones relativas al diseño y la gama de productos y servicios de 
Tabla No 2: Variable económica del Turismo Sostenible.

\begin{tabular}{|c|c|}
\hline Aspectos Económicos. & Elementos básicos que integran. \\
\hline \multirow[t]{4}{*}{ 1-Beneficios económicos del turismo. } & 1.1-Estacionalidad del turismo. \\
\hline & 1.2-Empleo turístico. \\
\hline & 1.3-Beneficios económicos para la comunidad. \\
\hline & 1.4-Competitividad y negocios turísticos. \\
\hline 2-Control de las actividades. & 2.1-Control del uso turístico. \\
\hline \multirow[t]{3}{*}{ 3-Organización del destino turístico. } & 3.1-Integración del turismo en la planeación. \\
\hline & 3.2-Control del desarrollo. \\
\hline & 3.3-Transporte relacionado con el turismo. \\
\hline \multirow[t]{4}{*}{ 4-Diseño de productos y servicios. } & 4.1-Creación de rutas turísticas. \\
\hline & 4.2-Oferta de variedades. \\
\hline & 4.3-Actividades de marketing. \\
\hline & 4.4- Imagen o marca del destino. \\
\hline \multirow[t]{2}{*}{ 5-Satisfacción de los turistas. } & 5.1-Satisfacción de los turistas. \\
\hline & 4.3-Actividades de marketing. \\
\hline
\end{tabular}

Fuente: Propia.

En la dimensión ambiental se recogen los aspectos relacionados con la conservación y protección de los recursos y ecosistemas naturales, que permiten analizar la viabilidad a largo plazo de la actividad en función de los efectos que tiene sobre el medio. Estos aspectos son los recogidos en la tabla No 3.

El primer aspecto es el grado de protección de los recursos naturales de valor mediante la conservacióny ampliación de las áreas naturales protegidas y el control de la intensidad de uso turístico de las mismas.

Un segundo aspecto recoge las cuestiones relativas a la necesidad de una gestión adecuada de los recursos naturales escasos como los hídricos y los energéticos.

En tercer lugar, se contempla la limitación del impacto ambiental de la actividad turística, con cuestiones tales como el tratamiento adecuado de las aguas residuales, los residuos sólidos y la reducción de los niveles de contaminación.

Finalmente, un último aspecto ambiental básico a destacar es la implantación de políticas y 
prácticas de gestión ambiental en el destino.

Para poner en marcha un modelo de turismo sostenible en el que se tengan en cuenta todos los aspectos básicos citados, son necesarias herramientas que permitan detectar la falta de sostenibilidad y, según el diagnóstico ofrecido, diseñar las actuaciones necesarias para alcanzar una situación más sostenible (Bossell, 1999; Pulselli et al., 2006).

De esta forma, en los últimos años la medición de la sostenibilidad ha pasado a ser uno de los temasmás tratados en la literatura (Mitchell, 1996), generándose medidas alternativas que dan prioridad a determinados aspectos del concepto.

La definición de cada medida del grado de sostenibilidad se realiza en función del análisis conceptual delobjetivo del que se parte (Hanley et al., 1999). Por ello, en nuestro caso necesitábamos un instrumento de medición definido en el marco de las instituciones internacionales, que pudiera adaptarse a la definición institucional que hemos presentado.

Tabla No 3: Variable ambiental del Turismo Sostenible.

\begin{tabular}{|c|c|}
\hline Aspectos Ambientales. & Elementos básicos que integran. \\
\hline 1-Protección de recursos naturales. & 1.1-Protección de ecosistemas. \\
\cline { 2 - 2 } & 1.2-Calidad de las aguas. \\
\hline 2-Gestión de recursos naturales. & 2.1-Gestión energética. \\
\cline { 2 - 2 } 3-Limitación del impacto ambiental. & 2.2-Disponibilidad y gestión del agua. \\
\cline { 2 - 2 } & 3.1-Tratamiento de las aguas residuales. \\
\cline { 2 - 2 } & 3.2-Gestión de los residuos sólidos. \\
\cline { 2 - 2 } & 3.3-Contaminación atmosférica. \\
\cline { 2 - 2 } & 3.4-Gestión del impacto de la infraestructura. \\
\hline 4-Gestión ambiental. & 4.1-Políticas y prácticas de gestión ambiental. \\
\hline
\end{tabular}

Fuente: Propia.

Según la OCDE (Organization for Economic Cooperation and Development, 2000), se distinguen dos enfoques de medición del grado de sostenibilidad:

1- El contable.

2- El analítico.

Dentro del enfoque contable se consideran dos tipos de medidas: por un lado, la medición realizada a través de las cuentas que conforman los Sistemas de Cuentas Nacionales y, por otro lado, las medidas agregadas formuladas a partir de dichas cuentas.

A pesar de los beneficios que ofrecen estos instrumentos, las dificultades teóricas y prácticas existentes para su estimación, el carácter unidimensional que prevalece en sus formulaciones, su carácter específico según el territorio en el que se evalúan...dan lugar a que éstas estén limitadas para realizar un análisis interterritorial a nivel local (Mitchell, 1996), no siendo fácilmente entendibles por agentes no 
expertos.

Así, decidimos optar por un enfoque de medición analítica que permitiera definir un instrumento que proporcione una evaluación multidimensional adecuada como herramienta de planificación local.

Dicho instrumento, según este enfoque, viene dado por un conjunto de "indicadores de turismo sostenible, entendiendo por tales las medidas que proporcionan la información necesaria para comprender mejor los vínculos y los impactos del turismo con respecto al entorno cultural y natural en el que se desenvuelve la actividad y del que es ampliamente dependiente" (OMT, 1995).

Se trata pues de medidas cuyos niveles absolutos y la dirección en que cambian, tienen como finalidadindicar si la región analizada presenta una situación más o menos sostenible (Comisión Europea, 1996). El análisis de la experiencia internacional nos permite afirmar que para la obtención de una medidaanalítica de sostenibilidad es necesario: en primer lugar, desagregar el objetivo turismo sostenible identificando los aspectos que constituyen cada dimensión; y, en segundo lugar, identificar los indicadores que permiten medir cada uno de los aspectos anteriores.

Aunque los indicadores elegidos se definen en función del análisis conceptual previo realizado, para garantizar que los valores de los mismos muestran avances hacia un estado más sostenible, los indicadores seleccionados deben cumplir los criterios de validez científica, representatividad, relevancia, fiabilidad, sensibilidad, carácter predictivo, comprensibilidad, comparabilidad, cuantificación, costeeficiencia, transparencia y cobertura geográfica (Romero et al., 2003).

De esta forma, se consigue una medida de sostenibilidad multidimensional ajustada al análisis conceptual del que se parte, compuesto por elementos fácilmente comprensibles por parte del usuario final.

Además, es una medida que puede aplicarse en niveles administrativos desagregados y que permite realizar análisis comparativos interterritoriales y de la evolución de la situación imperante.

Dada la idoneidad de este enfoque de medición, en el siguiente apartado realizamos un estudio metodológico que nos permita, por una parte, caracterizar el proceso de elaboración de indicadores y, por otra, determinar un procedimiento adecuado para nuestro estudio.

\section{MARCO METODOLÓGICO.}

En los estudios que realizan una medición analítica, la definición de los indicadores y su proceso de elaboración y obtención vienen determinados por los objetivos de los mismos y las preferencias de los analistas, lo que pone de manifiesto la inexistencia de un único procedimiento metodológico.

Para caracterizar el proceso de elaboración de indicadores, analizamos la literatura existente con el objetivo de determinar los aspectos comunes que se tienen en consideración, con independencia del concepto medido. Así, se diferencian dos grandes enfoques metodológicos (Sharpe, 2004, Nardo et al., 
2005):

1- El no-agregativo

2- El agregativo.

Dentro del enfoque no-agregativo consideramos los trabajos que utilizan como instrumento de medición un sistema de indicadores, cuyos componentes evalúan aspectos parciales y proporcionan la información necesaria para obtener un conocimiento comprehensivo del concepto evaluado.

Al analizar los procedimientos seguidos para la definición de sistemas, se pueden identificar cuatropasos básicos a seguir.

En primer lugar, es necesario establecer el contexto definiendo el concepto objeto de estudio, determinando el área o conjunto de unidades que son relevantes para el mismo e identificando los principales agentes o grupos de interés implicados.

Realizado esto, en segundo lugar, se define el objetivo o situación futura a alcanzar, con vistas a la cual se define el sistema, bien fijando una meta o estableciendo una dirección de cambio a seguir.

En tercer lugar, es necesario identificar, evaluar y seleccionar los indicadores del sistema.

Para ello, se genera una lista de indicadores potenciales y posteriormente se evalúa su idoneidad para lamedición del concepto en el contexto fijado en el primer paso, seleccionando finalmente los que integran el sistema con los criterios que se fijen a partir de una revisión de trabajos realizados en un contexto similar (Reed et al., 2006).

Finalmente, se aplica el sistema de indicadores, cuantificándolo y utilizándolo para la gestión y control dela consecución de los objetivos finales mediante la identificación de umbrales o el uso de benchmarks dereferencia para la interpretación de los valores de cada indicador del sistema (TwiningWard y Butler, 2002).

Para la obtención de un sistema de indicadores adecuado para realizar el estudio empírico que planteamos posteriormente, seguiremos estos pasos descritos utilizando el conocimiento experto recogido en investigaciones internacionales y utilizando las directrices de la OMT como referencia externa.

Dado el carácter desagregado de este instrumento de medición y la diversidad de aspectos que suele contener, parece indicado disponer de una medida que recoja el estado conjunto mostrado por cada unidad evaluada sin necesidad de analizar los indicadores iniciales por separado.

Así, muchos estudios optan por obtener medidas sintéticas a partir del sistema inicial mediante una combinación (o agregación) matemática de sus componentes (Saisana y Tarantola, 2002; Nardo et al., 2005b).

Este conjunto de trabajos es el que conforma el enfoque agregativo. A pesar de la subjetividad asociadaa las decisiones adoptadas al definir cada medida sintética, en la práctica éstas son herramientas 
muy útiles que aportan ventajas adicionales a las proporcionadas por el sistema de indicadores.

Así, permiten realizar análisis comparativos propios de los procedimientos de planificación, ilustran y evalúan objetivos complejos, permiten establecer tendencias para realizar procedimientos de control y seguimiento y prácticas de benchmarking, facilitando la interpretación de la información por parte de los usuarios finales.

Existen multitud de metodologías alternativas para la elaboración y obtención de indicadores sintéticos. Apesar de ello, al igual que en el enfoque anterior, el análisis realizado de los trabajos de este enfoquenos ha permitido identificar los pasos básicos a seguir para obtener indicadores sintéticos (Saisana y Tarantola, 2002; Sharpe y Salzman, 2003; Nardo et al., 2005a; Nardo et al., 2005).

En concreto, los procedimientos de obtención de indicadores sintéticos que hemos analizado son:

1- Indicadores sintéticos obtenidos otorgando a cada indicador inicial la misma importancia yagregando mediante una suma ponderada.

2- Indicadores sintéticos basados en métodos participativos, obtenidos mediante una suma ponderada son obtenidos a partir de las opiniones subjetivas mostradas por el conjunto de estudiantes y profesores. 3- Indicadores sintéticos definidos a partir de los resultados obtenidos al aplicar un sistema de indicadores, bien formulando escalas aditivas o agregando los valores de las componentes principales.

Con las conclusiones obtenidas del análisis de estos procedimientos, nos planteamos obtener indicadores estableciendo sinergias operacionales entre métodos ya existentes, que nos permita aprovechar sus ventajas y contrarrestar algunas limitaciones.

Propuesta de un sistema de indicadores de turismo sostenible para los destinos turísticos en el cantón Otavalo.

Para evaluar el grado de sostenibilidad de estos destinos, aplicamos los pasos descritos en este trabajo siguiendo las directrices de la OMT para definir un sistema de indicadores adaptado al concepto de turismo sostenible presentado anteriormente.

Así, dentro de cada dimensión conceptual, identificamos las cuestiones que son necesarias para poder planificar un destino bajo objetivos de sostenibilidad (World Tourism Organization, 2004).

Para la evaluación de las mismas, la OMT ofrece un listado indicativo de los indicadores teóricos alternativos más usados y relevantes para su medición, señalando en cada caso la variabilidad indicativa de una situación más sostenible en el destino y también el carácter clave o específico de los indicadores. En este sentido, se consideran claves los indicadores que evalúan cuestiones esenciales para gestionar el turismo en cualquier destino y los específicos que permiten gestionar factores importantes para el destino ligados a sus propias características. 
Para seleccionar los indicadores de nuestro sistema hemos tenido en cuenta la importancia del indicador para la planeación y gestión del destino, la disponibilidad de fuentes estadísticas para su cuantificación, el nivel espacial del análisis, así como los criterios básicos que garantizan que los indicadores muestran un avance hacia una situación más sostenible (Romero et al., 2003).

Asimismo, hemos completado la definición del sistema incluyendo aspectos e indicadores adicionales utilizados en investigaciones ya existentes, donde se definen sistemas de indicadores de sostenibilidad anivel local (Castro, 2004; Gallego y Moniche, 2005; Sancho y García, 2006).

De esta forma, proponemos un sistema de indicadores que se presentan en las figuras No: 4, 5 y 6 , indicándose en cada caso el aspecto básico, la cuestión específica evaluada y la dimensión conceptual ala que pertenecen.

De esta forma, el sistema posee una parte común formada por la información de tipo clave y otra parte diferenciada, en función del atractivo turístico analizado.

Tabla No 4: Indicadores de la Variable Social del Turismo Sostenible.

\begin{tabular}{|c|c|c|c|}
\hline $\begin{array}{l}\text { Aspectos básicos del } \\
\text { componente social. }\end{array}$ & Variable evaluada. & Indicador formador. & Porcentaje. \\
\hline \multirow[t]{7}{*}{$\begin{array}{l}\text { 1-Efectos socio- } \\
\text { culturales del turismo. }\end{array}$} & $\begin{array}{l}\text { 1.1-Capacidad de } \\
\text { servicios deportivos. }\end{array}$ & $\begin{array}{l}\text { 1.1- Dotación de } \\
\text { espacios deportivos. }\end{array}$ & \\
\hline & $\begin{array}{l}\text { 1.2-Capacidad de } \\
\text { servicios sanitarios. }\end{array}$ & $\begin{array}{c}\text { 1.2-Dotación de centros } \\
\text { sanitarios. }\end{array}$ & \\
\hline & \begin{tabular}{ll} 
1.3-Capacidad & de \\
servicios & de \\
\multicolumn{1}{c}{ transportes. } &
\end{tabular} & $\begin{array}{l}\text { 1.3-Dotación de } \\
\text { transporte de viajeros. }\end{array}$ & \\
\hline & $\begin{array}{l}\text { 1.4-Capacidad de } \\
\text { servicios financieros. }\end{array}$ & $\begin{array}{l}\text { 1.4-Dotación de } \\
\text { servicios financieros. }\end{array}$ & \\
\hline & $\begin{array}{c}\text { 1.5-Capacidad } \\
\text { servicios } \\
\text { farmacéuticos. }\end{array}$ & $\begin{array}{l}\text { 1.5-Dotación } \\
\text { farmacias. }\end{array}$ & \\
\hline & \begin{tabular}{l} 
1.6-Capacidad $\begin{array}{r}\text { para } \\
\text { prestar }\end{array}$ \\
\multicolumn{2}{c}{ servicios } \\
públicos.
\end{tabular} & $\begin{array}{l}\text { 1.6-Dotación } \\
\text { servicios públicos. }\end{array}$ & \\
\hline & $\begin{array}{cc}\text { 1.7-Capacidad } & \text { de } \\
\text { otros servicios. } & \end{array}$ & \begin{tabular}{cc} 
1.7- Dotación & de \\
establecimientos en el \\
\multicolumn{2}{c}{ sector servicios. }
\end{tabular} & \\
\hline 2-Seguridad pública. & $\begin{array}{c}\text { 2.1- Valoración de la } \\
\text { seguridad. }\end{array}$ & $\begin{array}{l}\text { 2.1- Valoración de la } \\
\text { seguridad al turista. }\end{array}$ & \\
\hline
\end{tabular}




\begin{tabular}{|c|c|c|c|}
\hline & $\begin{array}{l}\text { 2.2- Dispositivos } \mathrm{de} \\
\text { seguridad. }\end{array}$ & $\begin{array}{l}\text { 2.2- Dotación de } \\
\text { servicios de seguridad y } \\
\text { emergencia. }\end{array}$ & \\
\hline \multirow[t]{5}{*}{$\begin{array}{l}\text { 3-Conservación } \\
\text { patrimonio cultural. }\end{array}$} & $\begin{array}{l}\text { 3.1- Patrimonio bajo } \\
\text { protección cultural. }\end{array}$ & $\begin{array}{l}\text { 3.1- Número de sitios } \\
\text { protegidos. }\end{array}$ & \\
\hline & \begin{tabular}{|} 
3.2- Aportaciones para \\
protección \\
patrimonio.
\end{tabular} & 3.2- Voluntariosculturales. & \\
\hline & $\begin{array}{c}\text { 3.3- Uso } \\
\text { patrimonio. }\end{array}$ & $\begin{array}{c}\text { 3.3-Presión } \\
\text { patrimonio } \\
\text { cultural. }\end{array}$ & \\
\hline & $\begin{array}{l}\text { 3.4- Interpretación del } \\
\text { patrimonio. }\end{array}$ & $\begin{array}{l}\text { 3.4- Número de guías } \\
\text { expertos. }\end{array}$ & \\
\hline & $\begin{array}{l}\text { 3.5- Protección de las } \\
\text { tradiciones culturales. }\end{array}$ & $\begin{array}{l}\text { 3.5- Número de fiestas y } \\
\text { costumbres. }\end{array}$ & \\
\hline \multirow[t]{6}{*}{$\begin{array}{ll}\text { 4-Efectos } & \text { sobre de lala } \\
\text { estructura } & \end{array}$} & $\begin{array}{l}\text { 4.1- Mantenimiento del } \\
\text { nivel de población. }\end{array}$ & 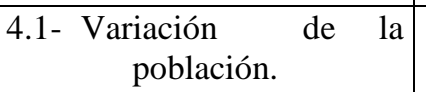 & \\
\hline & $\begin{array}{c}\text { 4.2-Incremento de } \\
\text { población }\end{array}$ & $\begin{array}{l}\text { 4.2- } \\
\begin{array}{l}\text { Porcentaje } \\
\text { población joven. }\end{array}\end{array}$ & \\
\hline & $\begin{array}{l}\text { 4.3- Envejecimiento dela } \\
\text { población. }\end{array}$ & \begin{tabular}{ll} 
4.3- Porcentaje & de \\
población mayor & no \\
\multicolumn{2}{c}{ activa. }
\end{tabular} & \\
\hline & $\begin{array}{l}\text { 4.4- Densidad } \mathrm{de} \\
\text { población. }\end{array}$ & $\begin{array}{l}\text { 4.4- Concentración de } \\
\text { población por superficie. }\end{array}$ & \\
\hline & 4.5- Nivelpoblación. de & 4.5- Saldo migratorio. & \\
\hline & & $\begin{array}{l}\text { 4.6- Crecimiento } \\
\text { vegetativo. }\end{array}$ & \\
\hline \multirow[t]{2}{*}{ 5-Carga social. } & $\begin{array}{l}\text { 5.1-Imposición de } \\
\text { cultural extrajera. }\end{array}$ & $\begin{array}{l}\text { 5.1- Porcentaje } \\
\text { población extranjera. }\end{array}$ & \\
\hline & $\begin{array}{l}\text { 5.2- Capacidad } \mathrm{de} \\
\text { carga social. }\end{array}$ & $\begin{array}{l}\text { 5.2- Población turística } \\
\text { por habitante local. }\end{array}$ & \\
\hline \multirow[t]{4}{*}{$\begin{array}{l}\text { 6-Efectos } \quad \text { sobre de ella } \\
\text { bienestar } \\
\text { población. }\end{array}$} & \begin{tabular}{lrl} 
6.1-Efecto & de & los \\
\multicolumn{2}{c}{ condicionantes } & \\
sociales & sobre & \\
longevidad & de & la la \\
población. & &
\end{tabular} & 6.1-Esperanza de vida. & \\
\hline & 6.2-Efectos sobre & 6.2-Variación de la renta & \\
\hline & renta. & disponible. & \\
\hline & $\begin{array}{l}\text { 6.3-Efectos sobre los } \\
\text { niveles educativos de } \\
\text { la población. }\end{array}$ & $\begin{array}{c}\text { 6.3- } \text { Porcentaje } \\
\text { población escolarizada } \\
\text { en niveles }\end{array}$ & \\
\hline
\end{tabular}




\begin{tabular}{|c|c|c|}
\hline & & obligatorios. \\
\hline & $\begin{array}{cc}\text { 6.4-Efectos sobre } & \text { la } \\
\text { situación } & \mathrm{de} \\
\text { dependencia } & \\
\text { poblacional. } & \end{array}$ & $\begin{array}{l}\text { 6.4-Índice } \\
\text { dependencia } \\
\text { demográfica. }\end{array}$ \\
\hline & $\begin{array}{c}\text { 6.5-Efectos sobre } \\
\text { acceso a la vivienda. }\end{array}$ & $\begin{array}{c}\text { 6.5- Valor catastral de } \\
\text { los inmuebles por } \\
\text { habitantes. }\end{array}$ \\
\hline $\begin{array}{l}\text { 7-Mejora del paisaje } \\
\text { urbano. }\end{array}$ & $\begin{array}{c}\text { 7.1- Rehabilitación de } \\
\text { edificios. }\end{array}$ & $\begin{array}{l}\text { 7.1- Porcentaje de } \\
\text { edificios rehabilitados. }\end{array}$ \\
\hline & $\begin{array}{l}\text { 7.2-Costo de } \\
\text { protección cultural. }\end{array}$ & $\begin{array}{l}\text { 7.2- } \\
\text { la rondos destinos a } \\
\text { rehabilitación } \\
\text { edificios. }\end{array}$ \\
\hline & $\begin{array}{l}\text { 7.3- Mejora del } \\
\text { entorno urbano. }\end{array}$ & $\begin{array}{c}\text { 7.3- Fondos destinados } \\
\text { a la mejora del entorno } \\
\text { urbano físico. }\end{array}$ \\
\hline
\end{tabular}

Fuente: Propia.

Tabla No 5: Indicadores de la Variable Económica del Turismo Sostenible

\begin{tabular}{|c|c|c|c|}
\hline $\begin{array}{l}\text { Aspectos básicos del } \\
\text { componente } \\
\text { económico. }\end{array}$ & Variable evaluada. & Indicador formador. & Porcentaje. \\
\hline \multirow{9}{*}{$\begin{array}{l}\text { 1-Beneficios } \\
\text { económicos } \\
\text { comunidad. }\end{array}$} & $\begin{array}{c}\text { 1.1-Volumen } \\
\text { demanda turística. }\end{array}$ & $\begin{array}{l}\text { 1.1-Número de turistas } \\
\text { recibidos. }\end{array}$ & \\
\hline & $\begin{array}{ccc}\text { 1.2-Duración } \\
\text { estancia. }\end{array}$ & 1.2-Estancia media. & \\
\hline & $\begin{array}{c}\text { 1.3-Ingresos generados } \\
\text { por el turismo. }\end{array}$ & 1.3-Gasto turístico. & \\
\hline & $\begin{array}{l}\text { 1.4- Inversión en } \\
\text { inmuebles. }\end{array}$ & $\begin{array}{l}\text { 1.4- Valor catastral de } \\
\text { los inmuebles. }\end{array}$ & \\
\hline & $\begin{array}{c}\text { 1.5-Empleo } \\
\text { generado. }\end{array}$ & $\begin{array}{|lr|}\begin{array}{l}\text { 1.5- Proporción } \\
\text { empleados en el } \\
\text { sector servicios. }\end{array} & \text { el } \\
\end{array}$ & \\
\hline & $\begin{array}{r}\begin{array}{r}\text { 1.6-Desempleo } \\
\text { destino. }\end{array} \\
\text { en }\end{array}$ & $\begin{array}{c}\text { 1.6-Tasa } \\
\text { desempleo. }\end{array}$ & \\
\hline & $\begin{array}{l}\text { 1.7- Inversiones en elsector } \\
\text { servicios. }\end{array}$ & $\begin{array}{l}\begin{array}{l}\text { 1.7- Volumen } \\
\text { inversiones } \\
\text { registradas. }\end{array} \\
\text { terciarias } \\
\end{array}$ & \\
\hline & 1.8-Comunicaciones. & $\begin{array}{l}\text { 1.8- Dotación } \\
\text { líneas en servicio. }\end{array}$ & \\
\hline & $\begin{array}{l}\text { 1.9- Renta disponible } \\
\text { por habitantes. }\end{array}$ & \begin{tabular}{|r}
$\begin{array}{l}\text { 1.9- Renta } \\
\text { declarada } \\
\text { habitantes. }\end{array}$ \\
por \\
\end{tabular} & \\
\hline \multirow[t]{3}{*}{\begin{tabular}{|c}
\multicolumn{2}{|c|}{ 2-Mantenimiento de la } \\
satisfacción de los \\
turistas.
\end{tabular}} & $\begin{array}{c}\text { 2.1-Satisfacción } \\
\text { del visitante. }\end{array}$ & $\begin{array}{l}\begin{array}{l}\text { 2.1-Nivel } \\
\text { satisfacción de } \\
\multicolumn{2}{c}{\text { duristas. }}\end{array} \\
\end{array}$ & \\
\hline & $\begin{array}{l}\text { 2.2-Satisfacción del } \\
\text { turista por la relación } \\
\text { calidad-precio. }\end{array}$ & \begin{tabular}{|c|}
$2.2-$ Percepción de la \\
relación \\
calidad \\
precio.
\end{tabular} & \\
\hline & $\begin{array}{c}\text { 2.3-Fidelidad de la } \\
\text { demanda. }\end{array}$ & $\begin{array}{l}\text { 2.3- Porcentaje de } \\
\text { turistas que vuelven a }\end{array}$ & \\
\hline
\end{tabular}




\begin{tabular}{|c|c|c|c|}
\hline & & visitar el destino. & \\
\hline & $\begin{array}{l}\text { 2.4-Satisfacción de la visita } \\
\text { de espacios }\end{array}$ & \begin{tabular}{|l}
$2.4-N i v e l$ \\
satisfacción de los visitantes \\
de los espacios r naturales \\
\multicolumn{2}{c}{ protegido. }
\end{tabular} & \\
\hline & $\begin{array}{l}\text { 2.5-Satisfacción de la visita } \\
\text { de los sitios culturales del } \\
\text { destino. }\end{array}$ & $\begin{array}{l}2.5 \text {-Nivel } \\
\text { satisfacción de los visitantes } \\
\text { de los sitios culturales del } \\
\text { destino. }\end{array}$ & \\
\hline 3-Control del desarrollo. & $\begin{array}{l}\text { 3.1- } \begin{array}{l}\text { Organización } \\
\text { espacio turístico. }\end{array} \\
\text { del }\end{array}$ & $\begin{array}{|lr|}\text { 3.1-Existencia } & \text { de } \\
\text { algún plan de } \\
\text { organización } \\
\text { afecte al turismo. }\end{array}$ & \\
\hline \multirow[t]{7}{*}{ 4-Oferta de variedad. } & $\begin{array}{l}\text { 4.1-Oferta } \\
\text { alojamiento turístico. }\end{array}$ & $\begin{array}{c}\text { 4.1-Plazas de } \\
\text { alojamiento ofertadas. }\end{array}$ & \\
\hline & $\begin{array}{l}\text { 4.2-Calidad de la ofertade } \\
\text { alojamiento turístico. }\end{array}$ & $\begin{array}{|cc|}\begin{array}{c}\text { 4.2- Plazas de } \\
\text { alojamiento de alta } \\
\text { categoría. }\end{array} & \\
\end{array}$ & \\
\hline & $\begin{array}{l}\text { 4.3-Oferta } \\
\text { alojamiento. }\end{array}$ & $\begin{array}{|cc|}\begin{array}{c}\text { 4.3-Dotación } \\
\text { establecimientos } \\
\text { alojamientos. }\end{array} & \text { de } \\
\end{array}$ & \\
\hline & $\begin{array}{c}\text { 4.4-Oferta de servicios } \\
\text { de restauración. }\end{array}$ & \begin{tabular}{|c|}
$\begin{array}{c}\text { 4.4-Plazas de } \\
\text { restauración ofertadas. }\end{array}$ \\
\end{tabular} & \\
\hline & $\begin{array}{l}\text { 4.5-Promoción de } \\
\text { experiencias turísticas. }\end{array}$ & $\begin{array}{c}\begin{array}{c}\text { 4.5-Dotación de } \\
\text { oficinas de información } \\
\text { turística. }\end{array} \\
\end{array}$ & \\
\hline & $\begin{array}{l}\text { 4.6-Promoción de } \\
\text { experiencias turísticas. }\end{array}$ & $\begin{array}{c}\begin{array}{c}\text { 4.6-Existencia de } \\
\text { página web propias. }\end{array} \\
\end{array}$ & \\
\hline & $\begin{array}{l}\text { 4.7-Oferta } \\
\text { actividades } \\
\text { ecoturísticas. }\end{array}$ & $\begin{array}{l}\text { 4.7-Servicios de oferta } \\
\text { ecoturística } \\
\text { complementaria. }\end{array}$ & \\
\hline \multirow[t]{3}{*}{$\begin{array}{l}\text { 5-Estacionalidad de la } \\
\text { actividad turística. }\end{array}$} & $\begin{array}{l}\text { 5.1- Estacionalidad de la } \\
\text { oferta alojamiento. }\end{array}$ & $\begin{array}{|lr|}5.1-\quad \text { Porcentaje } & \text { de } \\
\text { establecimientos } & \mathrm{de} \\
\text { alojamiento abierto } & \\
\text { todo el año. } & \\
\end{array}$ & \\
\hline & $\begin{array}{l}\text { 5.2-Estacionalidad de la } \\
\text { demanda. }\end{array}$ & \begin{tabular}{|l} 
5.2-Proporción entre el \\
número de turistas en \\
periodos de baja afluencia \\
respecto alos de afluencia \\
máxima.
\end{tabular} & \\
\hline & $\begin{array}{c}\text { 5.3-Estacionalidad } \\
\text { empleo turístico. }\end{array}$ & $\begin{array}{l}\text { 5.3-Porcentaje depuestos de } \\
\text { trabajo del sector turístico } \\
\text { que } \\
\text { son fijos. }\end{array}$ & \\
\hline \multirow[t]{2}{*}{ 6-Empleo turístico. } & $\begin{array}{l}\text { 6.1- Volumen de empleo } \\
\text { turístico. }\end{array}$ & $\begin{array}{|cr|}\begin{array}{l}\text { 6.1- Número } \\
\text { empleados en } \\
\text { sector turístico. }\end{array} & \text { el } \\
\end{array}$ & \\
\hline & $\begin{array}{l}\text { 6.2-Peso del empleoturístico } \\
\text { dentro del empleo total del } \\
\text { destino. }\end{array}$ & \begin{tabular}{l}
$6.2-\quad$ Porcentaje \\
empleados en el sector \\
turístico respecto al \\
empleo \\
\multicolumn{2}{c}{ total. }
\end{tabular} & \\
\hline \multirow[t]{3}{*}{$\begin{array}{cc}\text { 7-Transportes relacionados } \\
\text { con } & \text { elturismo. }\end{array}$} & $\begin{array}{l}\text { 7.1- Capacidad de los } \\
\text { servicios de transportes } \\
\text { públicos. }\end{array}$ & $\begin{array}{|ll|}\text { 7.1- Dotación } & \text { de } \\
\text { vehículos } & \text { de } \\
\text { transporte de viajeros. }\end{array}$ & \\
\hline & $\begin{array}{c}\text { 7.2-Acceso a través de } \\
\text { aeropuerto. }\end{array}$ & $\begin{array}{l}\text { 7.2- Tiempo de accesoal } \\
\text { aeropuerto más } \\
\text { cercano. }\end{array}$ & \\
\hline & 7.3-Acceso a través de & 7.3- Tiempo de acceso & \\
\hline
\end{tabular}




\begin{tabular}{|c|c|c|}
\hline & autopista. & a la autopista máscercana. \\
\hline & $\begin{array}{c}\text { 7.4-Acceso a través de } \\
\text { carretera. }\end{array}$ & $\begin{array}{c}\text { 7.4-Tiempo de accesoa la } \\
\text { carretera nacional } \\
\text { más cercana. }\end{array}$ \\
\hline & $\begin{array}{l}\text { 7.5-Acceso a través de } \\
\text { ferrocarril. }\end{array}$ & $\begin{array}{l}\text { 7.5-Tiempo de acceso a la } \\
\text { estación de ferrocarril de } \\
\text { acceso } \\
\text { más cercana. }\end{array}$ \\
\hline & $\begin{array}{l}\text { 7.6-Red de carreteras } \\
\text { para transporte público. }\end{array}$ & $\begin{array}{l}\text { 7.6-Densidad de la red } \\
\text { de carreteras. }\end{array}$ \\
\hline $\begin{array}{r}\text { 8-Competitividad } \\
\text { destino. }\end{array}$ & $\begin{array}{c}\text { 8.1-Tasas de ocupación en } \\
\text { alojamientosoficiales. }\end{array}$ & 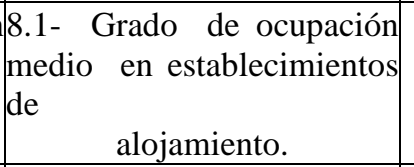 \\
\hline $\begin{array}{l}\text { 9-Creación de itinerariosy } \\
\text { rutas turísticas. }\end{array}$ & \begin{tabular}{|lc} 
9.1-Rutas & existentes en \\
espacios & naturales \\
protegidos. &
\end{tabular} & 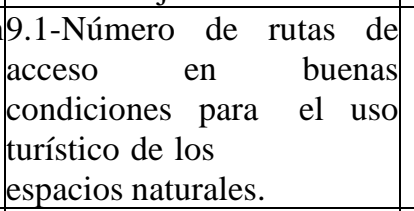 \\
\hline & $\begin{array}{l}\text { 9.2-Rutas turísticas } \\
\text { creadas. }\end{array}$ & $\begin{array}{c}\text { 9.2-Número de rutas } \\
\text { turísticas que incluyen al } \\
\text { destino en su } \\
\text { itinerario. }\end{array}$ \\
\hline & 9.3-Explotación de lasrutas. & \begin{tabular}{|c|} 
9.3-Número de guías \\
$\begin{array}{c}\text { expertos en } \\
\text { interpretación. }\end{array}$ \\
\end{tabular} \\
\hline 10-Infraestructuras. & $\begin{array}{l}\text { 10.1-Infraestructuras para } \\
\text { uso público de losespacios } \\
\text { protegidos. }\end{array}$ & $\begin{array}{l}\text { 10.1- Equipamiento de uso } \\
\text { público dentro de los } \\
\text { espacios naturales } \\
\text { protegidos. }\end{array}$ \\
\hline 11-Inversión cultural. & $\begin{array}{l}\text { 11.1-Costos de la } \\
\text { protección cultural. }\end{array}$ & $\begin{array}{l}\text { 11.1-Fondos destinos } \\
\text { a la rehabilitación de } \\
\text { edificios. }\end{array}$ \\
\hline 12-Aglomeración. & $\begin{array}{l}\text { 12.1-Distribución espacial } \\
\text { de los sitios } \\
\text { que se pueden visitar en } \\
\text { el destino. }\end{array}$ & $\begin{array}{l}\text { 12.1-Número de } \\
\text { recorridos e itinerarios } \\
\text { dentro del cantón. }\end{array}$ \\
\hline
\end{tabular}

$$
\text { Fuente: Propia. }
$$

Tabla No 6: Indicadores de la Variable Ambiental del Turismo Sostenible.

\begin{tabular}{|c|c|c|c|}
\hline $\begin{array}{l}\text { Aspectos básicos del } \\
\text { componente } \\
\text { ambiental. }\end{array}$ & Variable evaluada. & Indicador formador. & Porcentaje. \\
\hline \multirow[t]{4}{*}{$\begin{array}{l}\text { 1- Protección de los } \\
\text { ecosistemas. }\end{array}$} & $\begin{array}{c}\text { 1.1-Protección de } \\
\text { recursos naturales. }\end{array}$ & \begin{tabular}{|c|}
$\begin{array}{c}\text { 1.1-Superficie } \\
\text { protegida. }\end{array}$ \\
natural \\
\end{tabular} & \\
\hline & $\begin{array}{c}\text { 1.2-Integridad de los } \\
\text { ecosistemas. }\end{array}$ & $\begin{array}{c}\text { 1.2-Porcentaje de las zonas } \\
\text { naturales habilitadas } \\
\text { como suelocompactado para } \\
\text { suutilización por los } \\
\text { visitantes. }\end{array}$ & \\
\hline & $\begin{array}{l}\text { 1.3-Valor ecológico delas } \\
\text { zonas naturales. }\end{array}$ & $\begin{array}{c}\text { 1.3-Número de } \\
\text { especies presentes en } \\
\text { el destino. }\end{array}$ & \\
\hline & $\begin{array}{l}\text { 1.4-Protección de los } \\
\text { recursos naturales. }\end{array}$ & $\begin{array}{c}\text { 1.4-Superficie calificada } \\
\text { como zona } \\
\text { natural protegida. }\end{array}$ & \\
\hline $\begin{array}{l}\text { 2- Calidad de las aguas } \\
\text { marinas. }\end{array}$ & 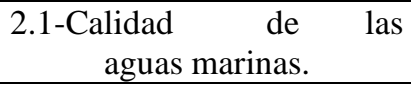 & $\begin{array}{|cc|}2.1-C a l i d a d & \text { de } \\
\text { aguas de baños. }\end{array}$ & \\
\hline 3- Gestión Energética. & 3.1-Energía. & 3.1-Consumo & \\
\hline
\end{tabular}




\begin{tabular}{|c|c|c|}
\hline & & energía. \\
\hline & $\begin{array}{l}\text { 3.2-Energía } \\
\text { renovable. }\end{array}$ & $\begin{array}{c}\text { 3.2-Porcentaje de consumo } \\
\text { energéticode recursos } \\
\text { renovables. }\end{array}$ \\
\hline $\begin{array}{l}\text { 4-Disponibilidad } \\
\text { gestión del agua. }\end{array}$ & 4.1-Consumo de agua. & 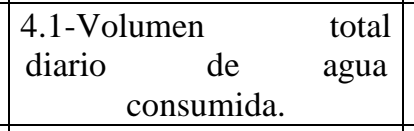 \\
\hline & $\begin{array}{c}\text { 4.2-Reutilización } \\
\text { agua. }\end{array}$ & $\begin{array}{l}\text { 4.2- Volumen de agua } \\
\text { reutilizada atribuible al } \\
\text { turismo. }\end{array}$ \\
\hline 5- Aguas residuales. & 5.1-Tratamiento. & $\begin{array}{l}\text { 5.1- Volumen de } \\
\text { aguas residuales que } \\
\text { reciben tratamiento. }\end{array}$ \\
\hline & $\begin{array}{cc}\text { 5.2-Instalaciones } \\
\text { tratamiento. }\end{array}$ & $\begin{array}{l}\text { 5.2-Existencia de } \\
\text { depuradoras de aguas } \\
\text { residuales. }\end{array}$ \\
\hline $\begin{array}{l}\text { 6- Gestión de residuossólidos } \\
\text { urbanos. }\end{array}$ & \begin{tabular}{|c|}
$\begin{array}{c}\text { 6.1-Producción } \\
\text { residuos. }\end{array}$ \\
\end{tabular} & \begin{tabular}{|c|}
$\begin{array}{c}6.1-\text { Volumen } \\
\text { residuos producidos. }\end{array}$ \\
\end{tabular} \\
\hline & $\begin{array}{l}\text { 6.2-Residuos reciclados } \\
\text { (vidrio). }\end{array}$ & $\begin{array}{l}\text { 6.2-Volumen } \\
\text { residuos reciclados con } \\
\text { respecto alvolumen total de } \\
\text { residuos. }\end{array}$ \\
\hline & $\begin{array}{l}\text { 6.3-Valoración de la } \\
\text { limpieza del destino. }\end{array}$ & $\begin{array}{c}\text { 6.3-Percepción de la } \\
\text { limpieza del destino } \\
\text { por parte del turista. }\end{array}$ \\
\hline & $\begin{array}{c}\text { 6.4-Instalaciones } \\
\text { tratamiento. }\end{array}$ & \begin{tabular}{lr}
$6.4-$ Existencia & de \\
instalaciones & de \\
tratamiento & de \\
residuos & sólidos \\
\multicolumn{2}{c}{ urbanos. } \\
\end{tabular} \\
\hline & $\begin{array}{c}\text { 6.5-Recogida selectivade } \\
\text { papel cartón. }\end{array}$ & $\begin{array}{c}\begin{array}{l}\text { 6.5-Dotación } \\
\text { contenedores } \\
\text { papel-cartón. }\end{array} \\
\text { de }\end{array}$ \\
\hline & $\begin{array}{l}\text { 6.6-Residuos reciclados } \\
\text { (papel-cartón). }\end{array}$ & $\begin{array}{l}\text { 6.6-Volumen de papel } \\
\text { y cartón recogido. }\end{array}$ \\
\hline & $\begin{array}{l}\text { 6.7-Recogida selectiva } \\
\text { de vidrio. }\end{array}$ & \begin{tabular}{cc|}
$\begin{array}{c}\text { 6.7-Dotación } \\
\text { contenedores } \\
\text { vidrio. }\end{array}$ & de \\
\end{tabular} \\
\hline 7-Contaminación atmosférica. & 7.1-Contaminación acústica. & $\begin{array}{c}\text { 7.1.1-Nivel diurno de } \\
\text { contaminación } \\
\text { acústica. }\end{array}$ \\
\hline & & $\begin{array}{c}\text { 7.1.2- Nivel nocturnode } \\
\text { contaminación } \\
\text { acústica. }\end{array}$ \\
\hline & $\begin{array}{c}\text { 7.2- } \\
\begin{array}{c}\text { Emisiones } \\
\text { contaminantes. }\end{array}\end{array}$ & $\begin{array}{lr}\text { 7.2- Niveles } & \text { de } \\
\text { emisión } & \text { de } \\
\begin{array}{c}\text { contaminantes } \\
\text { atmósfera. }\end{array} & \text { la } \\
\end{array}$ \\
\hline $\begin{array}{c}\text { 8- Gestión del impactovisual } \\
\text { de } \\
\begin{array}{c}\text { da } \\
\text { infraestructura } \\
\text { instalaciones. }\end{array}\end{array}$ & $\begin{array}{l}\text { 8.1-Impacto de las } \\
\text { construcciones. }\end{array}$ & $\begin{array}{|lr|}\begin{array}{l}8.1-\text { Niveles } \\
\text { emisión } \\
\begin{array}{c}\text { contaminantes } \\
\text { atmósfera. }\end{array}\end{array} & \begin{array}{r}\text { de } \\
\text { de } \\
\text { la }\end{array} \\
\end{array}$ \\
\hline & 8.2-Estado de erosión. & $\begin{array}{lr}8.2-\text { Densidad } & \text { de } \\
\text { construcción } & \text { por } \\
\text { unidad de superficie. }\end{array}$ \\
\hline & $\begin{array}{|cc|}\begin{array}{c}8.3-\text { Conservación } \\
\text { paisaje del destino. }\end{array} \\
\end{array}$ & \begin{tabular}{|c|}
$\begin{array}{c}\text { 8.3-Superficie } \\
\text { destinada a paisajes. }\end{array}$ \\
\end{tabular} \\
\hline & $\begin{array}{c}\text { 8.4-Impacto de la red } \\
\text { vial. }\end{array}$ & $\begin{array}{c}\text { 8.4-Densidad de la red } \\
\text { de carreteras. }\end{array}$ \\
\hline
\end{tabular}




\begin{tabular}{|c|c|c|}
\hline \multirow[t]{5}{*}{ 9- Intensidad de uso. } & 9.1-Intensidad turística. & $\begin{array}{l}\text { 9.1-Turistas recibidos } \\
\text { por superficie. }\end{array}$ \\
\hline & 9.2-Uso del suelo. & $\begin{array}{l}\text { 9.2-Construcciones } \\
\text { desocupadas. }\end{array}$ \\
\hline & $\begin{array}{c}\text { 9.3-Intensidad } \\
\text { turística. }\end{array}$ & $\begin{array}{ll}\text { 9.3-Número } & \text { de } \\
\text { operadores turísticos } & \text { con } \\
\text { licencia en el } & \\
\text { destino. }\end{array}$ \\
\hline & $\begin{array}{c}\text { 9.4-Intensidad de usode las } \\
\text { zonas naturales. }\end{array}$ & $\left|\begin{array}{lr}\text { 9.4-Número } & \text { de } \\
\text { visitantes } & \text { por } \\
\text { superficie protegida. }\end{array}\right|$ \\
\hline & $\begin{array}{c}\text { 9.5- Uso del suelo } \\
\text { agrícola. }\end{array}$ & $\begin{array}{c}\text { 9.5-Superficie dedicada } \\
\text { tareas } \\
\text { agrícolas. }\end{array}$ \\
\hline 10- Gestión ambiental. & $\begin{array}{l}\text { 10.1-Organismo gestor } \\
\text { en materia ambiental. }\end{array}$ & $\begin{array}{l}\text { 10.1-Existencia de } \\
\text { unidad administrativa } \\
\text { de medio ambiente. }\end{array}$ \\
\hline $\begin{array}{l}\text { 11- Percepción } \\
\text { limpieza. }\end{array}$ & $\begin{array}{l}\text { 11.1-Valoración por parte de } \\
\text { turista de la limpieza. }\end{array}$ & $\begin{array}{l}\text { 11.1-Nivel de } \\
\text { satisfacción de la demanda } \\
\text { con respectoa la calidad de } \\
\text { la } \quad \text { limpieza. }\end{array}$ \\
\hline
\end{tabular}

Fuente: Propia.

Definido el sistema, asignamos las variables más adecuadas en cada caso que, considerando la información disponible, nos permitiera cuantificar los indicadores de forma directa o indirecta.

Para ello tomamos como referencia los trabajos especializados que definen indicadores de sostenibilidad a nivel cantonal mencionados anteriormente, así como trabajos elaborados por instituciones públicas que recogen experiencias y directrices generales para la cuantificación de indicadores.

Para la cuantificación del sistema hemos elaborado una base de datos propia recopilando la información estadística desagregada a nivel cantonal existente. Puesto que el sistema de indicadores recoge aspectos de muy diversa naturaleza, ha sido necesario utilizar múltiples fuentes elaboradas por diferentes instituciones, procurando siempre usar una misma fuente para cuantificar un mismo indicador en todos los destinos.

Al realizar un análisis estadístico exploratorio de la base de datos, los indicadores de cada dimensión en los aspectos contemplados en el sistema.

\section{ANÁlisis DE RESULTADOS DE LA PROPUESTAS DE INDICADORES PARA EL TURISMO SOSTENIBLE.}

Para analizar la sostenibilidad del turismo en el destino Otavalo hemos considerados las características de las zonas sostenibles, aplicando una encuesta a estudiantes de la Licenciatura en Turismo y conjuntamente a profesores de la Universidad.

Como resultado de esta fase se obtuvieron la siguiente respuesta para cada objetivo evaluado en laencuesta las cuales se describen: 
Valorar algún sistema de indicadores para el Turismo sostenible.

Respuestas

Tabla No 7: Valoración de sistemas de indicadores para el turismo sostenible.

\begin{tabular}{|c|r|}
\hline $\mathrm{Si}$ & 13 \\
\hline No & 18 \\
\hline total & 31 \\
\hline
\end{tabular}

Fuente: Propia.

Gráfico No 1: Valoración de sistemas de indicadores para el turismo sostenible.

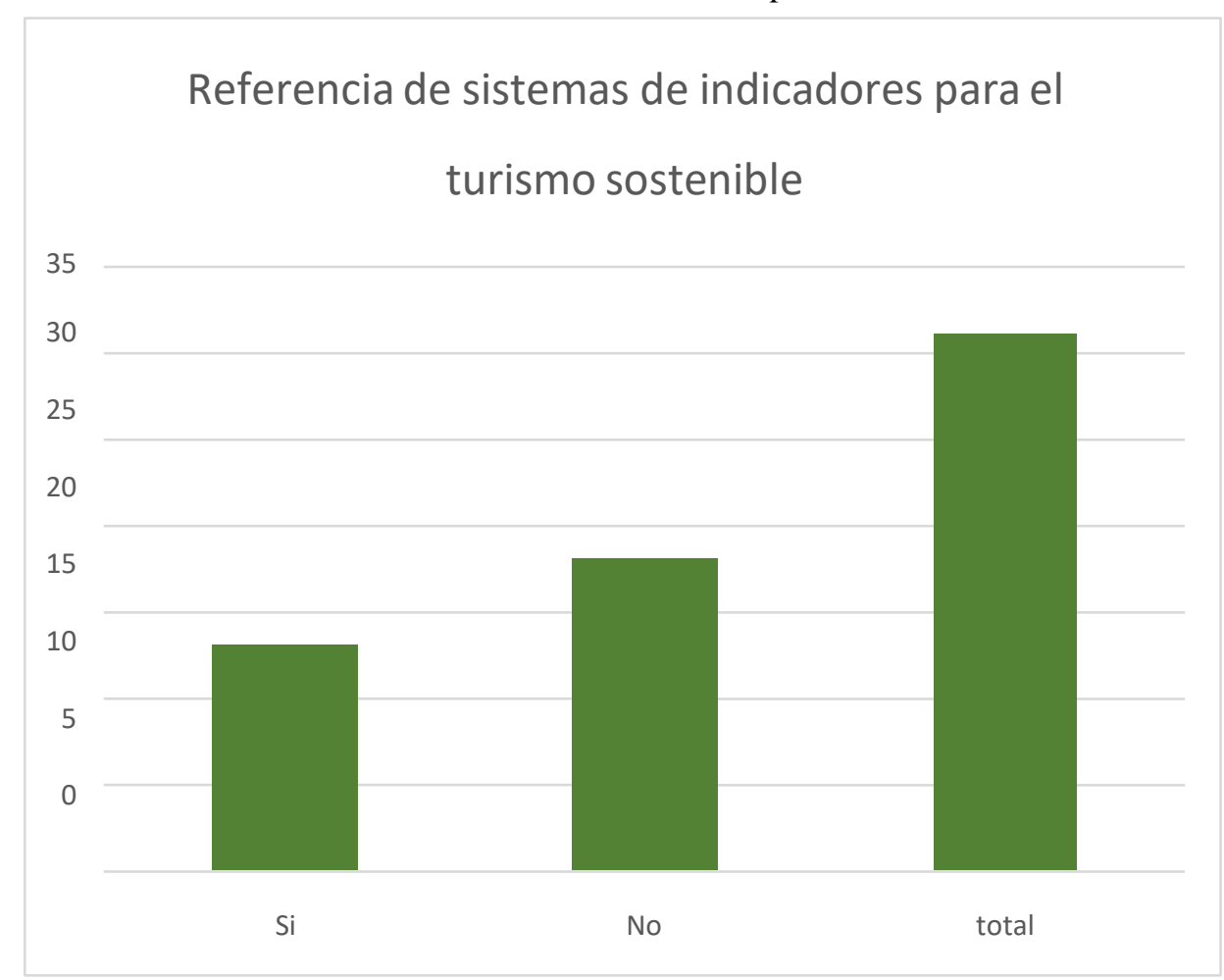

Fuente: Propia.

Evaluar los impactos de las dimensiones del turismo sostenible.

Respuesta

Tabla No 8: Evaluación de impactos en las dimensiones del turismo sostenible.

\begin{tabular}{|c|c|c|c|c|c|c|}
\hline \multirow{2}{*}{ Dimensión } & 5 & 4 & 3 & 2 & 1 & \multirow{2}{*}{ Total } \\
\cline { 2 - 6 } & (alto) & (medio alto) & (medio) & (medio bajo) & (bajo) & \\
\hline Social & 6 & 5 & 2 & 7 & 11 & 31 \\
\hline Económico & 1 & 9 & 3 & 3 & 15 & 31 \\
\hline Medio Ambiental & 4 & 3 & 6 & 4 & 14 & 31 \\
\hline
\end{tabular}

Fuente: Propia. 
Gráfico No 2: Evaluación de impactos en las dimensiones del turismo sostenible.

\section{Impactos en las dimensiones del turismo sostenible.}

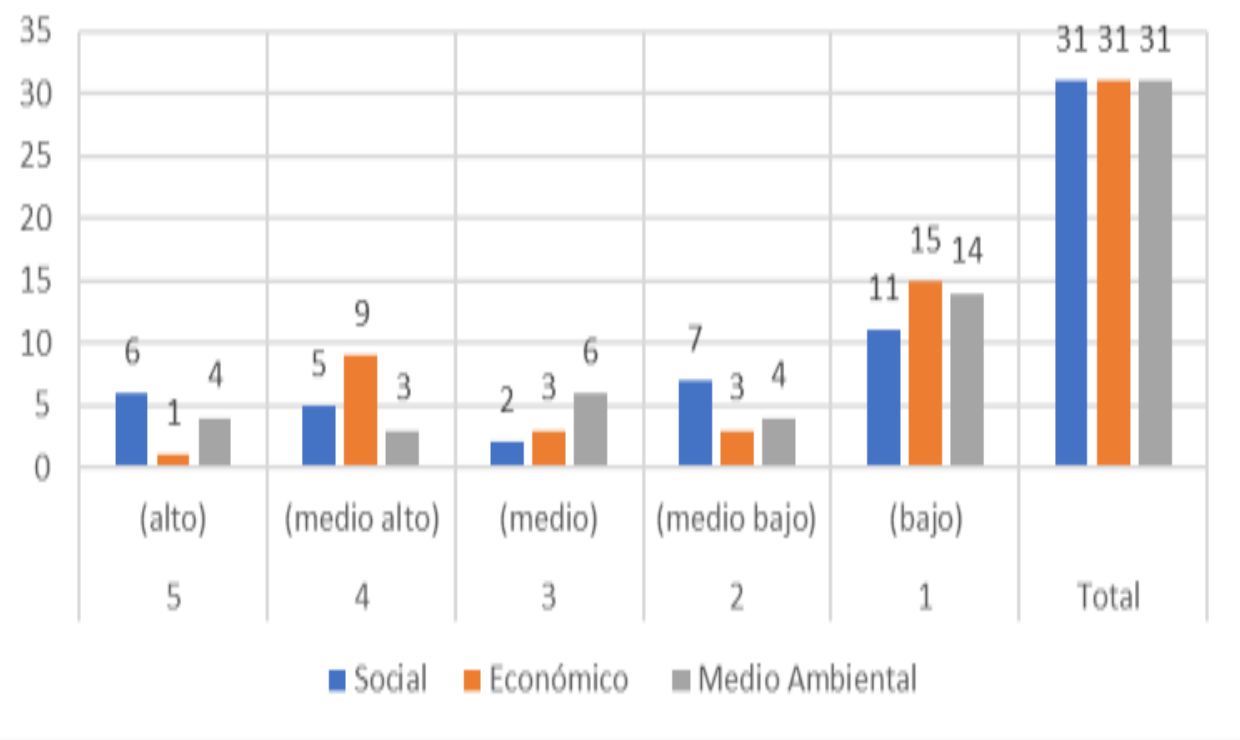

Fuente: Propia.

Determinar los métodos para evaluar el grado de sostenibilidad.

Tabla No 9: Métodos para evaluar el grado de sostenibilidad del turismo sostenible.

\begin{tabular}{|c|c|c|r|}
\hline Métodos & Posición 1 & Posición 2 & TOTAL \\
\hline Contable & 19 & 12 & 31 \\
\hline Analítico & 12 & 19 & 31 \\
\hline
\end{tabular}

Fuente: Propia.

Gráfico No 3: Métodos para evaluar el Grado de sostenibilidad

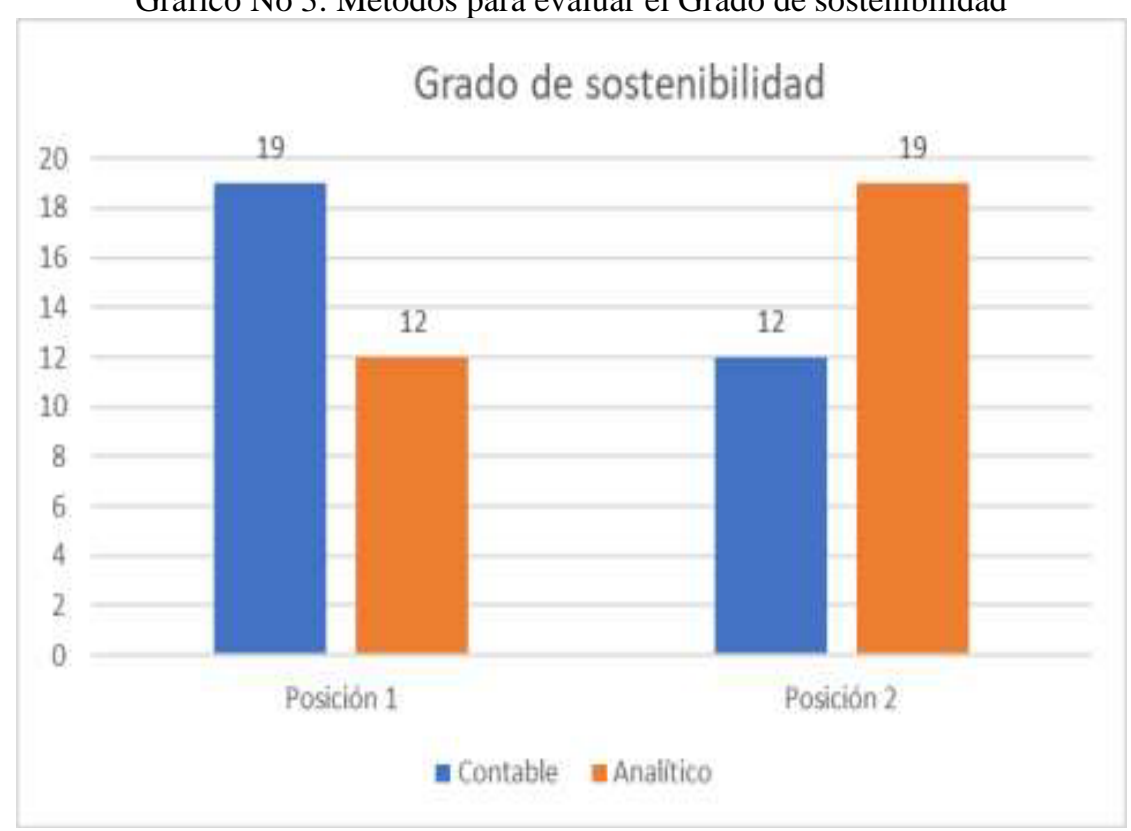

Fuente: Propia. 
Ejecutar la proyección de un sistema de indicadores sintéticos.

Tabla No 10. Sistema de Indicadores sintéticos

\begin{tabular}{|l|c|}
\hline \multicolumn{1}{|c|}{ Indicadores } & Resultados \\
\hline $\begin{array}{l}\text { Utilizar métodos s participativos que nos permitan identificar los indicadoressegún el } \\
\text { entorno. }\end{array}$ & 30 \\
\hline Solo tener presente opiniones subjetivas mostradas por quienes integren elproceso. & 5 \\
\hline Diseñar escalas aditivas componentes principales. & 29 \\
\hline Determinar un indicador inicial de suma importancia. & 27 \\
\hline TOTAL & 91 \\
\hline
\end{tabular}

Fuente: Propia

Gráfico No 4: Sistema de Indicadores sintéticos

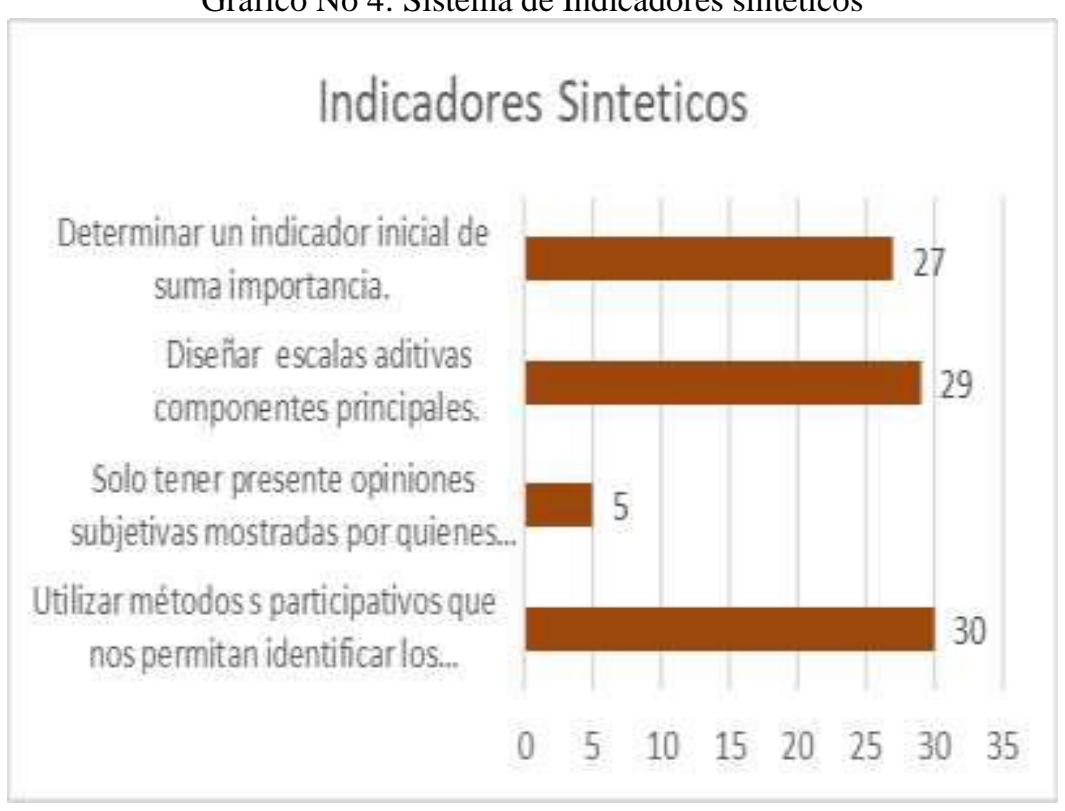

Fuente: Propia.

\section{CONCLUSIONES}

En el presente trabajo se ofrece una definición operativa del turismo sostenible desglosada en tres dimensiones (social, económica y medioambiental) a las que damos un contenido pormenorizado siguiendo las directrices de la OMT.

Para la puesta en práctica de este concepto adoptamos un enfoque de medición analítica utilizando indicadores de turismo sostenible.

Para su obtención, hemos realizado un análisis metodológico que nos ha permitido fijar los pasos básicos a seguir para definir un sistema de indicadores y agregar su información en una medidasintética.

A partir de las conclusiones extraídas en el análisis con estudiantes y profesores de la carrera de turismode la Universidad Otavalo, hemos definido un procedimiento de obtención de indicadores que permiten trabajar con una información contenida en el sistema y con unos resultados más fáciles de interpretar. 
Esta base de datos no sólo sirve de guía para la cuantificación del sistema propuesto, sino que muestra, en cierta medida, la capacidad de la información estadística actual para realizar un análisis multidimensional de sostenibilidad, señalando así mismo sus carencias. 


\section{BIBLIOGRAFÍA.}

- Diaz-Balteiro, L. and Romero, C., (2004) Sustainability of forest management plans: a discrete goal programming approach. J. Environ. Manage.

- Clarke, J., A (1997) framework of approach to sustainable tourism. J. Sustain. Tourism,

- Hardy, A., Beeton, R.J.S. and Pearson, L., (2002) Sustainable tourism: an overview of the concept and its position in relation to conceptualisations of tourism. J. Sustain. Tourism,

- Holden, A.,(2000) Environment and Tourism (Routledge, Taylor and Francis Group, Londres.

- Hunter, C., (2002) Aspects of the sustainable tourism debate from a natural resources perspective, in Sustainable Tourism. A Global Perspective,

- Ávila, R., Iniesta, A., Herrero, D., de Juan, J., Aguirre, G., Guereña, A., Morera, C., Beluche, G., Aguilar, P., Zambrano, D., Ruiz, R., Buglass, L., Kamp, C. and Giraldo, A., (2002) Turismo Sostenible (EIPALA, Colección problemas internacionales, Madrid,

- Dachary, A.C. and Arnáiz, S. M., (2002) Globalización, Turismo y Sustentabilidad (Universidad de Guadalajara, México.

- $\quad$ Fullana, P. and Ayuso, S., (2002) Turismo Sostenible Rubes, Barcelona.

- Organization for Economic Co-operation and Development, Frameworks to Measure Sustainable Development (2000) Organization for Economic Co-operation and Development Publications Service, Paris

- Organización Mundial del Turismo (OMT),(2005) Lo que Todo Gestor Turístico Debe Saber. Guía Práctica para el Desarrollo y Uso de Indicadores de Turismo Sostenible Organización Mundial del Turismo, Madrid.

- $\quad$ Romero, E.M., Pérez, F. and Sande, J.J., (2003) La Valoración del Desarrollo Sostenible: Una Propuesta Metodológica. Andalucía Ecológica, Medio Ambiente, Sevilla.

- Castro, J.M.,(2004) Indicadores de Desarrollo Sostenible Urbano: Una Aplicación paraAndalucía Consejería de Economía y Hacienda, Junta de Andalucía, Sevilla.

- Gallego, I. and Moniche, A., (2005) Sistema de indicadores territoriales para un destino turístico en Conferencia de la OMT Iguazú, Argentina/Brasil/Paraguay

- Sancho, A. y García, G., (2006) ¿Qué indica un indicador? Análisis comparativo en los destinos turísticos. Revista de Análisis Turístico. 